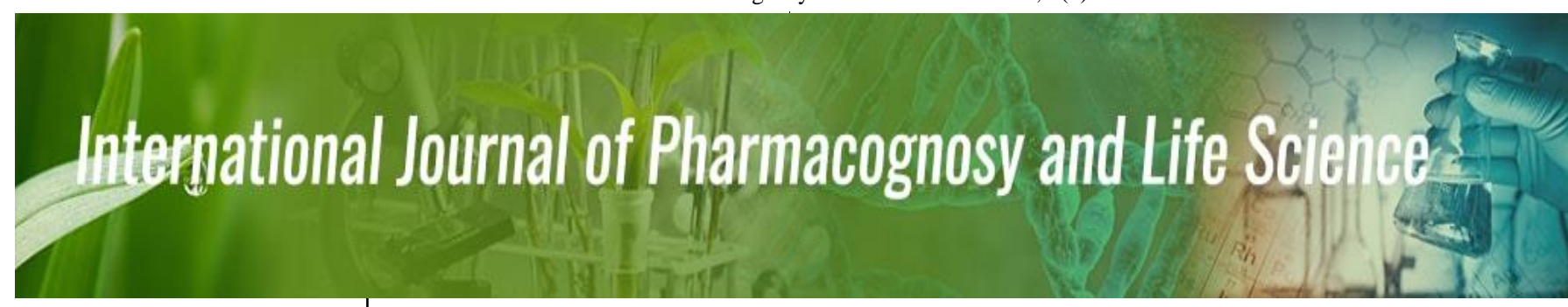

E-ISSN: 2707-2835

P-ISSN: 2707-2827

IJPLS 2020; 1(2): 06-13

Received: 05-05-2020

Accepted: 07-06-2020

\section{Yogesh T Sonawane}

Department of Pharmacognosy,

Saraswathi Vidya Bhavan's College of

Pharmacy, Sonarpada, Kalyan Shil

road, Dombivli, Thane, Maharashtra,

India

\section{Sushil S Pmipare}

Department of Pharmacognosy,

Saraswathi Vidya Bhavan's College of

Pharmacy, Sonarpada, Kalyan Shil

road, Dombivli, Thane, Maharashtra,

India

\section{Chetan A Chaudhari}

Department of Pharmacognosy,

Saraswathi Vidya Bhavan's College of Pharmacy, Sonarpada, Kalyan Shil

road, Dombivli, Thane, Maharashtra, India

Naveenkumar P Jain

Department of Pharmacognosy,

Saraswathi Vidya Bhavan's College of

Pharmacy, Sonarpada, Kalyan Shil

road, Dombivli, Thane, Maharashtra,

India

SC Pal

Department of Pharmacognosy,

Saraswathi Vidya Bhavan's College o Pharmacy, Sonarpada, Kalyan Shil road, Dombivli, Thane, Maharashtra, India

\section{Chhaya H Gadgoli}

Department of Pharmacognosy,

Saraswathi Vidya Bhavan's College of Pharmacy, Sonarpada, Kalyan Shil

road, Dombivli, Thane, Maharashtra,

India

Vinod A Bairagi

Department of Pharmacognosy,

Saraswathi Vidya Bhavan's College of

Pharmacy, Sonarpada, Kalyan Shil

road, Dombivli, Thane, Maharashtra,

India

\section{Sunita A Govilkar}

Department of Pharmacognosy,

Saraswathi Vidya Bhavan's College of Pharmacy, Sonarpada, Kalyan Shil road, Dombivli, Thane, Maharashtra, India

\section{Aher Bhaska}

Department of Pharmacognosy, Saraswathi Vidya Bhavan's College of Pharmacy, Sonarpada, Kalyan Shil road, Dombivli, Thane, Maharashtra, India

\section{Corresponding Author:} Yogesh T Sonawane

Department of Pharmacognosy, Saraswathi Vidya Bhavan's College of Pharmacy, Sonarpada, Kalyan Shil road, Dombivli, Thane,

Maharashtra, India

\title{
Evaluation of wound healing activity of flowers of Woodfordia fruticosa Kurz
}

\section{Yogesh T Sonawane, Sushil S Pmipare, Chetan A Chaudhari, Naveenkumar P Jain, SC Pal, Chhaya H Gadgoli, Vinod A Bairagi, Sunita A Govilkar and Aher Bhaskar}

\author{
DOI: https://doi.org/10.33545/27072827.2020.v1.i2a.11
}

\begin{abstract}
Aim: Woodfordia fruticosa (Lythraceae) commonly called as 'Dhatakipuspha' in India. In Ayurveda, The fresh flower of $W$. fruticosa has been reported to stop bleeding in emergency cuts, while the dried flower powder to heal wounds more efficiently. Traditionally Woodfordia fruticosa Kurz is used in wound healing by tribes of Chhattisgarh, India. There was no scientific evidence justifying the use of Woodfordia fruticosa for treating wounds, therefore the present study was aimed at evaluation of wound healing activity of the plant. This research did not receive any specific grant from funding agencies in the public, commercial, or not-for-profit sectors.

Materials and Methods: In the present study the flowers of Woodfordia fruticosa were studied for wound healing activity by incorporating the methanolic and total aqueous extract in simple ointment base B.P. in concentrations of $1 \%(\mathrm{w} / \mathrm{w})$ and $2 \%(\mathrm{w} / \mathrm{w})$. Ointments were also prepared using yashad bhasma $(1.25 \% \mathrm{w} / \mathrm{w})$ (equivalent zinc concentration $0.95 \% \mathrm{w} / \mathrm{w})$ and yashad bhasma $(0.625 \% \mathrm{w} / \mathrm{w})$ (equivalent zinc concentration $0.45 \% \mathrm{w} / \mathrm{w}$ and $0.56 \% \mathrm{w} / \mathrm{w}$ ) in combination with methanolic and total aqueous extract $(1 \% \mathrm{w} / \mathrm{w})$ in simple ointment base B.P. Wound healing activity was studied in the wound models in rats viz. excision and incision. In case of the excision wound model, wound contraction, period of epithelization and hydroxyproline content in the scab were studied, while incision wound model was evaluated by determining tensile strength of the newly formed skin.

Results: Treatment of wound with ointment containing $2 \%(\mathrm{w} / \mathrm{w})$ the methanolic and total aqueous and yashad bhasma $(0.625 \% \mathrm{w} / \mathrm{w})$ in combination with the methanolic and total aqueous extract $(1 \% \mathrm{w} / \mathrm{w})$ exhibited significant $(P<0.001)$ wound healing activity. The activity of the formulation may be due to the tannins present in the methanolic and total aqueous extract and zinc ions from the yashad bhasma which play major role in wound healing process.

Conclusion: The methanolic and total aqueous extract exhibited good wound healing activity probably due to presence of tannins constituents and also due to presence of Zinc in Yashad bhasma.
\end{abstract}

Keywords: Woodfordia fruticosa, flowers, Dhatakipuspha

\section{Introduction}

The skin is the largest and among the most complex organs of the body. The skin is a unique and remarkable organ that is the outer covering of the body. Wound is a clinical entity and is as old as mankind, often possesses problem in clinical practice. A lot of research has been envisaged to develop the better healing agents and it has been a challenging task to discover healing agents and keep up pace with problems encountered (Schwartz SI., 2006) ${ }^{[20]}$.

Wound may be defined as a type of physical trauma in where the skin is torn, cut or punctured (an open wound), or where blunt force trauma causes a contusion (a closed wound). In pathology, it specifically refers to a sharp injury, which damages the dermis of the skin. Wound healing or wound repair is the body's natural process of regenerating dermal and epidermal tissue. Wounds can be broadly categorized as having either an acute or a chronic etiology including bites, burns, surgical wound abrasion, laceration or acute inflammatory phase followed by synthesis of collagen and the extracellular macromolecules which are later remolded to form, scar (Deodhar and Rana, 1997) ${ }^{[5]}$.

Wound healing consists of an orderly progression of events that re-establish the integrity of the damaged tissue in three phases mainly inflammatory, proliferation and remodeling stages. 
Alterations in any of these steps can lead to delay in healing process or even the inability for dermal wound healing (Mavioso, 2003) ${ }^{[14]}$.

The inflammatory phase begins immediately after injury, first with vasoconstriction that favors homeostasis and releases inflammation mediators. The proliferative phase is characterized by granulation tissue proliferation formed mainly by fibroblast and the angiogenesis process. The remodeling stage is characterized by reformulations and improvement in the components of the collagen fiber that increases the tensile strength (Mandelbaum et al., 2003) ${ }^{[13]}$. Healing requires the collaborative efforts of many different tissues and cell lineages. It involves platelet aggregation and blood clotting, formation of fibrin, an inflammatory response to injury, alteration in the ground substances, angiogenesis and re-epithelialization.

Healing is not complete until the disrupted surfaces are firmly knit by collagen (Govindrajan et al., 2007) ${ }^{[7]}$. Medicinal plants have been used since time immemorial for treatment of various ailments of skin and dermatological disorders especially cuts, wounds and burns (Govindrajan et al., 2007) ${ }^{[7]}$.

Woodfordia fruticosa Kurz, (Lythraceae), commonly known as dhataki pushpa, is a plant of tropical and subtropical region with a long history of medicinal use. It is useful in the preparation of Ayurvedic fermented drugs called 'Aristha's and Asava's', and is also useful in thirst, dysentery, leprosy, blood diseases, leucorrhoea, piles and toothache. The extract from the flowers are used in folklore medicine for treatments of like bowel complaint, rheumatism, hematuria and dysuria (Das P.K., 2007) ${ }^{[4]}$. Flowers have exhibited Anti-fertility (Khushalani H., 2006) ${ }^{[10]}$, Hepatoprotective (Chandan B.K., 2008) ${ }^{[3]}$, In vitro Anti-bacterial (Parekh J., 2007) [19], Anti-pepticulcer, Immuno modulatory (Kroes B. H., 1993) [12] and an Inhibitor of DNA Topoisomerase II (Kadota S., 1997) ${ }^{[9]}$.

The flower has been reported to contain tannins, flavonoides, anthraquinones glycosides and polyphnoles. It also contain ellagic acid and gallic acid, hecogenin, naringenin 7-glucoside, kaempferol 3-Oglucoside, isoschimawalin A, Woodfordins A, B, C, D, E, and F (Das P.K, 2007) ${ }^{[4]}$. The plant is found including to be very useful in traditional systems of medicines like Ayurveda.

In Ayurveda, flower of W. fruticosa Kurz finds its utility in arresting bleeding and skin disorders, however, the literature survey revealed that no scientific study has been carried out on wound healing activity. Bhasma are Ayurvedic preparations, in which pure metal is treated with certain Ayurvedic decoctions and then subjected to high temperature to burn the metal in a closed cupola/crucible. The mineral ash that remains behind is called "Bhasma" of that metal. Calcinated zinc oxide containing chiefly zinc oxide is known for its mild astringent and antiseptic properties, due to which wound healing is accelerated.

An Ayurvedic preparation containing zinc in the form of Calcinated zinc oxide is utilized in the present study to evaluate efficacy of the bhasma in combination with the extract. In the present study, an effort has been made to establish wound healing potential of the methanolic and total aqueous extract of the flowers in combination with Yashad bhasma, using different models.

\section{Materials and Methods}

\subsection{Materials}

Flowers of the plant W. fruticosa Kurz was procured from the local market, Mumbai. The flowerswere authenticated at Agharkar Research Institute, Pune by carrying out macroscopic and microscopic evaluation. The voucher specimen of the same has been deposited (voucher specimen no.1/F025).

\subsection{Preparation of the extract}

The air-dried crude drug was pulverized to obtain coarse powder. The powdered drug $(150 \mathrm{gm})$ was defatted by extracting with pet-ether $\left(60-80{ }^{\circ} \mathrm{C}\right)$ using Soxhlet Extractor. The defatting process was followed by extraction of the powdered drug with methanol and distilled water with Soxhlet extractor. The extract thus obtained was concentrated by recovering the solvent by Rotary Flash Evaporator. The concentrated extract was then evaporated to dryness in vacuum oven at temperature not more than $50^{\circ} \mathrm{C}$ (yield: $6.7 \% \mathrm{w} / \mathrm{w}$ and $9.5 \% \mathrm{w} / \mathrm{w}$ ). The dried extract was stored at $2-8^{\circ} \mathrm{C}$ in refrigerator. The extract was further used for the evaluation of wound healing activity.

\subsection{Phytochemical analysis}

The methanolic and total aqueous extract was tested qualitatively for detection of presence of different phytoconstituents by performing various qualitative chemical tests.

\subsection{HPTLC fingerprinting study}

Preliminary phytochemical analysis revealed presence of tannins. The flower is reported to contain Ellagic acid and Gallic acid as tannins compounds respectively. Therefore, the qualitative HPTLC analysis was carried out using HPTLC (Silica gel $\mathrm{GF}_{254}$ ) plates and Toulene: Ethyl acetate: Formic acid in the ratio 5: 4: $1(\mathrm{v} / \mathrm{v})$ as mobile-phase for Ellagic acid and Gallic acid respectively. Sample detection was done by UV absorbance at $280 \mathrm{~nm}$. $\mathrm{R}_{f}$ and $\lambda$ max of the respective bands were recorded. Quantitative HPTLC study was also performed for the determining the content of Ellagic acid (Bioxmax) and Gallic acid (Krishna Chem) in the methanolic and total aqueous extract.

\subsection{Animals}

The healthy Wistar albino rats of either sex, weighing 150 $200 \mathrm{~g}$, were housed under standard environmental conditions of temperature and humidity $\left(25 \pm 0.50{ }^{\circ} \mathrm{C}\right)$ and $12 \mathrm{~h}$ light/dark cycle) were utilized for the studies. The animals were fed with standard pellet diet and water ad libitum. The animal studies were performed in the institute with due permission from Institutional Animal Ethical Committee (registration no. 704/CPCSEA, India dated 25/8/2003).

\subsection{Preparation of test ointments}

The methanolic and total aqueous extract and Yashad Bhasma were incorporated into Simple Ointment Base BP and the following Formulations were prepared:

CT: A Simple Ointment Base B.P. was used as control preparation in the study and it was prepared by triturating method. The ingredients and their proportions used are mentioned in the (Table 1)

The base was utilized for preparation of the following formulations.

M1 and A1: The methanolic and total aqueous extract was incorporated in the concentrations viz. $1 \% \mathrm{w} / \mathrm{w}$ into Simple Ointment Base B.P. by trituration method. 
M2 and A2: The methanolic and total aqueous extract was incorporated in the concentrations viz. $2 \% \mathrm{w} / \mathrm{w}$ into Simple Ointment Base B.P. by trituration method.

M3: Yashad bhasma was incorporated in concentration of $1.25 \% \mathrm{w} / \mathrm{w}$ (equivalent to $\mathrm{Zn}+{ }^{2} 0.95 \% \mathrm{w} / \mathrm{w}$ ) into simple ointment base B.P. by trituration method.

M4 and A3: Yashad bhasma and the methanolic extract was incorporated in concentration of $0.62 \% \mathrm{w} / \mathrm{w}$ (equivalent to $\mathrm{Zn}+{ }^{2} 0.45 \% \mathrm{w} / \mathrm{w}$ ) and the total aqueous extract (equivalent to $\mathrm{Zn}+{ }^{2} 0.56 \% \mathrm{w} / \mathrm{w}$ ) was incorporated in concentration $0.5 \%$ w/w into simple ointment base B.P. by trituration method.

STD: Betadine ointment (Marketed by Win Medicare, New Delhi) containing Povidone Iodine IP-5\%w/w was used as standard preparation in the study.

These formulations were applied topically on wounds twice a day.

Table 1: Composition of Simple Ointment Base

\begin{tabular}{|c|c|c|}
\hline S. No. & Ingredients & Quantity(\% w/w) \\
\hline 1. & White soft paraffin & 85 \\
\hline 2. & Cetostearyl alcohol & 5 \\
\hline 3. & Hard paraffin & 5 \\
\hline 4. & Wool fat & 5 \\
\hline
\end{tabular}

\subsection{Analysis of Yashad bhasma}

Yashad bhasma (Baidyanath Co. Batch no.47, Mfg. date: 9/08) and the ointments M3, M4 and A3 were analyzed for the $\mathrm{Zn}^{+2}$ content. The content of zinc was determined using inductively coupled plasma atomic emission spectroscopy available at sophisticated analytical instrument facility- IIT, Powai, Mumbai.

\subsection{Acute dermal toxicity}

The acute dermal toxicity testing of the ointment containing the methanolic and total aqueous extract was done by applying the Ointments containing methanolic and total aqueous extract of the highest concentrations of $2 \%(\mathrm{w} / \mathrm{w})$ amongst the all preparations and ointment containing the yashad bhasma on the shaved back of the rats. The OECD guidelines no. 402 (OECD guidelines, 1987) were followed for the study. Animals were observed for the sign of redness and itching for $24 \mathrm{hrs}$.

\subsection{Wound healing activity}

The animals were grouped into three major group's viz. control, standard and the test with six animals in each group. The control group was treated with simple ointment base B.P. The standard group was treated with Betadine [Win Medicare containing 5\% (w/w) povidone iodine, lot no. PJ0109] ointment. The test groups were treated with ointment formulations M1, M2, M3, M4, A1, A2 and A3.

\subsubsection{Excision wound model}

The rats were anesthetized by administering ketamine (Neon laboratories ltd, batch number SM20125) $(0.5 \mathrm{ml} / \mathrm{kg} \mathrm{b}$. w. i.p.). A full thickness of the excision wound of circular area (approx. $500 \mathrm{~mm}^{2}$ ) and $2 \mathrm{~mm}$ depth was inflicted on the shaved back of the rats 30 min later, the administration of ketamine injection. The wounds were then clean with cotton to remove blood. The wounding day was considered as day 0 . The wounds were treated with topical application of the ointment preparations mentioned above, till the wounds were completely healed. The wounds were monitored and the area of wound was measured on 4, 6, 8, 10, 12, 14, 16 post-wounding days by tracing the wounds on transparency sheet. The mean \% wound closure is reported in Table 2. The period of epithelization was calculated as the number of days required for falling of the Escher. (Nayak et al., 2007) [17]. Wound healing rate was expressed as\% wound closure and it was calculated using the following formula (Muthusamy et al., 2008) ${ }^{[16]}$ :

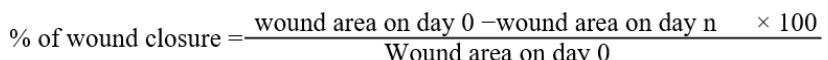

Where $n=$ number of days 4 th, 8 th, 12 th, $16^{\text {th }}$ and $20^{\text {th }}$ day.

Table 2: Effect of topical application of various formulations containing Methanolic Extract and Total aqueous extract of W. fruticosa flowers on epithelization of Excised wound in rat.

\begin{tabular}{|c|c|c|c|c|c|}
\hline GRPS & $\mathbf{4}^{\text {th }}$ day & $\mathbf{8}^{\text {th }}$ day & $\mathbf{1 2}^{\text {th }}$ Day & $\mathbf{1 6}^{\text {th }}$ day & $\mathbf{2 0}^{\text {th }}$ day \\
\hline & \multicolumn{5}{|c|}{ Mean Percentage of wound contraction $\underline{\mathbf{}}$ SEM } \\
\hline CT & $10 \pm 0.36$ & $35.06 \pm 0.38$ & $47.78 \pm 0.54$ & $74.51 \pm 0.32$ & $91.46 \pm 0.23$ \\
\hline STD & $30.5 \pm 0.43$ & $53.48 \pm 0.94$ & $83.78 \pm 1.1$ & $92.74 \pm 0.49$ & $98.01 \pm 0.30$ \\
\hline M1 & $13.98 \pm 0.48^{* *}$ & $58.04 \pm 0.34^{* *}$ & $84.86 \pm 0.86^{* *}$ & $89.16 \pm 0.17^{* *}$ & $94.47 \pm 0.40^{* * *}$ \\
\hline M2 & $17.07 \pm 0.04^{* *}$ & $68.22 \pm 0.11^{* *}$ & $86.85 \pm 0.31^{* *}$ & $91.62 \pm 0.41^{* *}$ & $98.61 \pm 0.37^{* * *}$ \\
\hline M3 & $19.96 \pm 0.29^{* * *}$ & $55.24 \pm 0.86^{* * *}$ & $71.62 \pm 0.44^{* * *}$ & $86.27 \pm 0.35^{* * *}$ & $96.17 \pm 0.38^{* * *}$ \\
\hline M4 & $27.61 \pm 0.69^{* *}$ & $74.95 \pm 1.27^{* * *}$ & $90.38 \pm 0.25^{* * *}$ & $93.57 \pm 0.68^{* * *}$ & $100^{* * *}$ \\
\hline A1 & $12.65 \pm 0.37^{* *}$ & $53.50 \pm 1.80^{* *}$ & $82.09 \pm 0.62^{* *}$ & $87.38 \pm 0.42^{* *}$ & $93.47 \pm 0.39^{* * *}$ \\
\hline A2 & $15.78 \pm 0.52^{* *}$ & $63.82 \pm 0.32^{* *}$ & $84.37 \pm 0.47^{* *}$ & $89.50 \pm 0.42^{* *}$ & $95.75 \pm 0.48^{* * *}$ \\
\hline A3 & $24.97 \pm 0.73^{* *}$ & $68.78 \pm 0.45^{* * *}$ & $87.65 \pm 0.38^{* * *}$ & $91.44 \pm 0.53^{* * *}$ & $99.53 \pm 0.25^{* * *}$ \\
\hline F CAL & 221.66 & 176.60 & 465.36 & 169.85 & 73.696 \\
\hline
\end{tabular}

$\mathrm{F}_{\mathrm{TAB}} 3.17$

$\mathrm{n}=6$ Animals in each group

The treated groups are compared by ANOVA test with the control group.

$* * * P<0.001, * * P<0.01, * P<0.05$

\subsubsection{Incision wound model}

The rats were anesthetized by administering ketamine (Neon laboratories ltd, batch number SM20125) $(0.5 \mathrm{ml} / \mathrm{kg}$ b. w. i.p.).Two paravertibral Incision wounds of about $6 \mathrm{~cm}$ in length and $2 \mathrm{~mm}$ in depth were made with sterile scalpel on the shaved back of the rats 30 min later, the administration of ketamine injection (Fig. 6A). The parted skin was kept together and stitched with black silk at $0.5 \mathrm{~cm}$ intervals (Fig.8) using surgical thread (no. 000) and a curved needle (no. 9). The continuous thread on both the wound edges 
were tightened for good closure of the wounds. The wounds of animals in the different groups were treated with topical application of the Ointment formulations as described above, for the period of 10 days. The wounding day was considered as day 0 . When wounds were cured thoroughly, the sutures were removed on the $8^{\text {th }}$ post-wounding day (Fig. 9) and the tensile strength of the skin that is the weight in grams required to break open the wound was measured by tensiometer (Kokane et al., 2009) ${ }^{[11]}$ for both the sides on the $10^{\text {th }}$ day is reported in Table 3.

Tensile strength was calculated using the following formula (Diwan et al., 2008) ${ }^{[6] \text { : }}$

$$
\text { Tensile strength }=\frac{\text { breaking strength }(\mathrm{g})}{\text { Cross-sectional area of skin }\left(\mathrm{mm}^{2}\right)}
$$

The results are presented as mean weight in gms required to break open the wound of both the sides \pm S.E.M

Table 3: Effect of topical application of Formulations containing Methanolic and Total Aqueous extract of $W$. fruticosa flowers on Tensile strength of the newly formed skin in incision wound created in albino rats.

\begin{tabular}{|c|c|c|c|c|c|c|c|}
\hline \multirow{3}{*}{ Groups } & \multicolumn{7}{|c|}{ Mean Tensile strength in gm } \\
\hline & \multicolumn{6}{|c|}{ Animals } & \multirow[t]{2}{*}{ Mean \pm S.E.M } \\
\hline & 1 & 2 & 3 & 4 & 5 & 6 & \\
\hline CT & 385 & 390 & 390 & 385 & 395 & 380 & $387.5 \pm 2.14$ \\
\hline STD & 530 & 550 & 540 & 530 & 520 & 530 & $533.33 \pm 4.21$ \\
\hline M1 & 530 & 545 & 520 & 535 & 555 & 540 & $537.5 \pm 4.95 * * *$ \\
\hline M2 & 550 & 530 & 550 & 590 & 600 & 570 & $565 \pm 10.87 * * *$ \\
\hline M3 & 480 & 510 & 450 & 520 & 480 & 500 & $490 \pm 10.32 * * *$ \\
\hline M4 & 590 & 595 & 610 & 615 & 580 & 585 & $595.8 \pm 10.87 * * *$ \\
\hline A1 & 505 & 520 & 489 & 500 & 509 & 525 & $508 \pm 5.37 * * *$ \\
\hline $\mathrm{A} 2$ & 490 & 510 & 530 & 560 & 590 & 540 & $536.66 \pm 14.53^{* * *}$ \\
\hline A3 & 580 & 560 & 590 & 610 & 540 & 620 & $583.33 \pm 12.29 * * *$ \\
\hline $\mathrm{F}_{\mathrm{CAL}}$ & & 44.36 & & $\mathbf{F}_{\mathrm{TAR}}$ & & & 3.17 \\
\hline
\end{tabular}

$\mathrm{n}=6$ Animals in each group

The treated groups are compared by ANOVA test with the control group.

$* * * P<0.001, * * P<0.01, * P<0.05$

\subsubsection{Estimation of biochemical marker}

Circular excision wound with approximate area of $500 \mathrm{~mm}^{2}$ was inflicted using the procedure described in 2.9.1. The wounds were treated with topical application of ointments as described above for 10 days. The scab was removed on $11^{\text {th }}$ post wounding day and dried in oven at $110{ }^{\circ} \mathrm{C}$. The hydroxyproline content in dried scab was determined by the method described by Bergman and Loxley (1963) ${ }^{[2]}$. Hydroxyproline from the scab was extracted using concentrated Hydrochloric acid followed by reaction between amino group of hydroxyproline with pdimetylaminobenzaldeyde to develop red colour. The red colour thus produced, was measured on Spectrophotometer (Elico-SL 159) at 558nm using the reagent blank The results are presented in Table 4 as mean hydroxyproline content/
$500 \mathrm{mg}$ of $\mathrm{scab} \pm$ S.E.M

\subsection{Statistical analysis}

Results obtained from the wound healing experiments have been expressed as mean \pm SEM and were compared with the corresponding control group (simple ointment B.P.) by applying ANOVA test (Mukherjee et al., 2000) ${ }^{[15]}$.

\section{Results}

\subsection{Phytochemical analysis}

Qualitative phytochemical analysis of methanolic and total aqueous extract of flowers $W$. fruticosa revealed presence of tannins and flavonoids.

\subsection{HPTLC fingerprinting study}

Chromatographic analysis of reference standard of Ellagic acid and Gallic acid indicated single spots with $\mathrm{R}_{f} 0.39$ and $\mathrm{R}_{f} 0.53$ (Fig.1) which coincide with spots in methanolic and total aqueous extract (Fig. 2 and Fig 3). UV spectra of the standard and the sample peak were also matching which also confirms the presence of Ellagic acid and Gallic acid in methanolic and total aqueous extract (Fig. 4- Fig.5). The content of Ellagic acid and Gallic acid in the methanolic and total aqueous extract was found out from the calibration curves of respective reference standards.

The methanolic extract was found to contain $4.21 \% \mathrm{w} / \mathrm{w}$ and $3.62 \% \mathrm{w} / \mathrm{w}$ of Ellagic acid and Gallic acid respectively. The total aqueous extract was found to contain $6.70 \% \mathrm{w} / \mathrm{w}$ and $4.75 \% \mathrm{w} / \mathrm{w}$ of Ellagic acid and Gallic acid respectively.

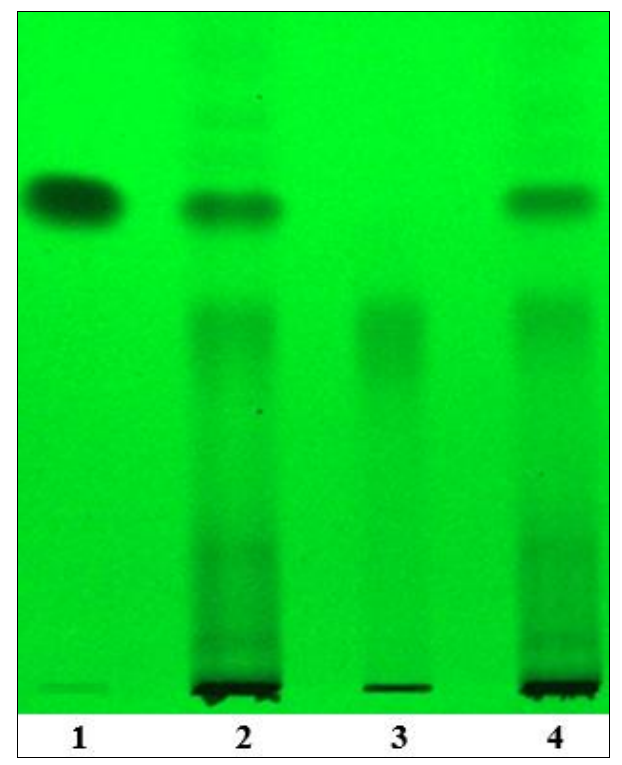

Fig 1: HPTLC Plate image for Detection of Eallgic Acid and Gallic Acid in the Methanolic and Total aqueous extract of flowers of $W$. fruticosa

\section{At 254nm}

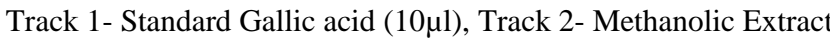
$(10 \mu \mathrm{l})$

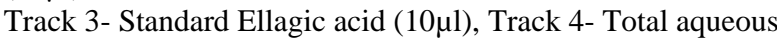
Extract $(10 \mu 1)$ 


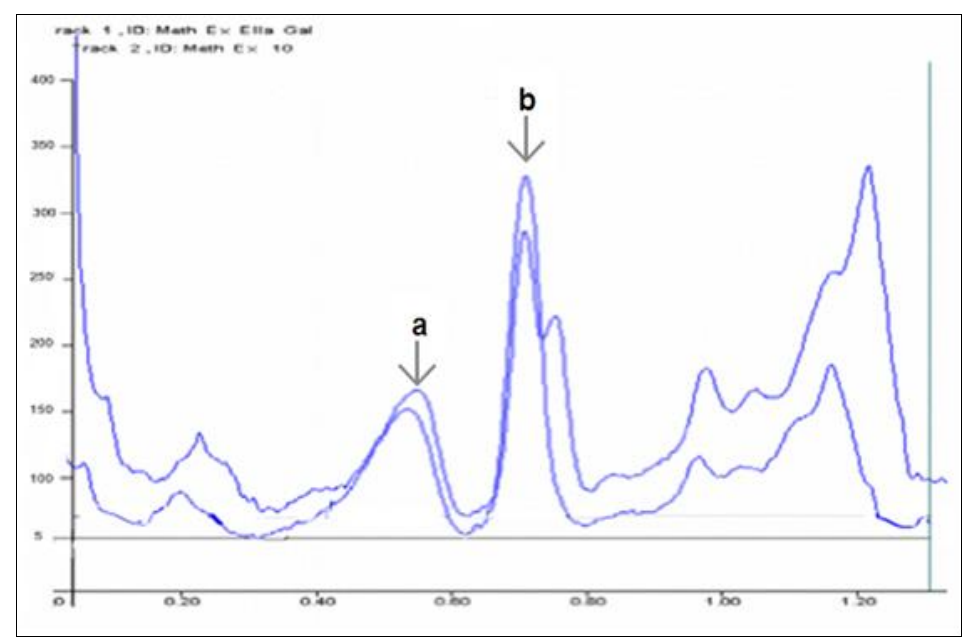

Fig 2: Fingerprint of Methanolic extract of $W$. fruticosa and the Methanolic extract spiked with reference Standards of Ellagic Acid and Note: Gallic Acid.

a: The methanolic extract + ellagic acid (1000ppm)

b: The methanolic extract + gallic acid (1000ppm)

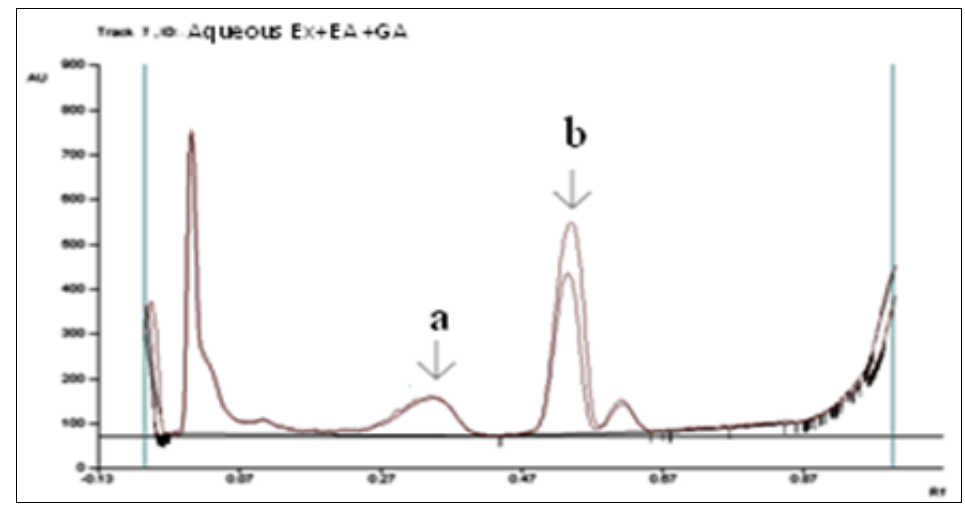

Fig 3: Fingerprint of Total aqueous extract of W. fruticosa and the Total aqueous extract spiked with reference Standards of Ellagic Acid and Note: Gallic Acid.

a: The total aqueous extract + ellagic acid (1000ppm)

b: The total aqueous extract + gallic acid $(1000 \mathrm{ppm})$

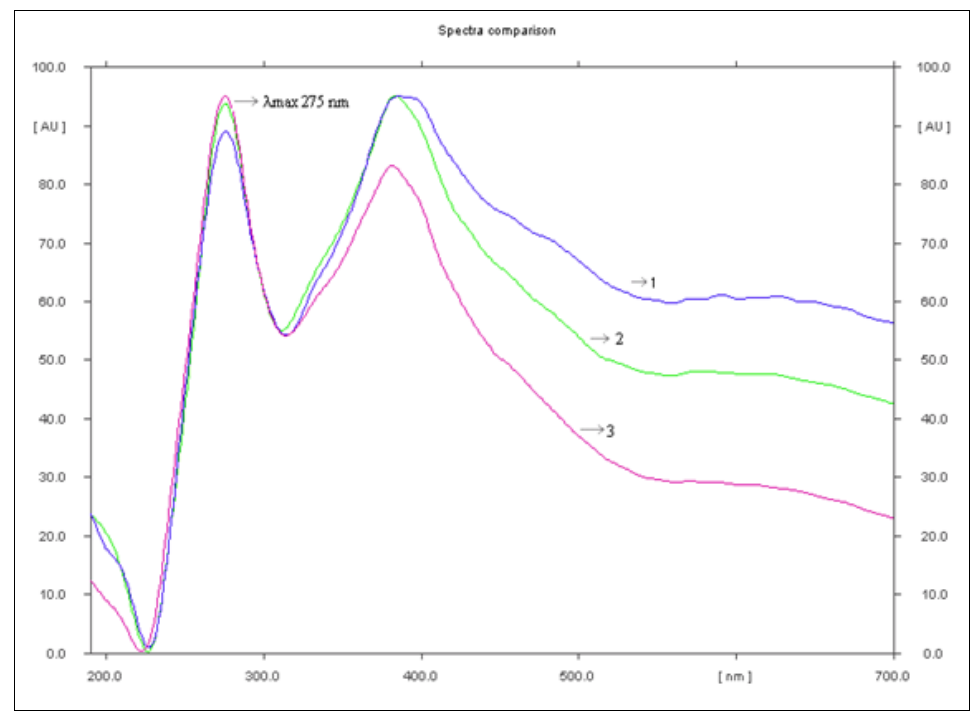

Fig 4: Superimposition of the UV spectra of Ellagic acid (Reference Standard) the Methanolic and the Total aqueous extract of flowers of W. fruticosa Kurz.

1. $\quad$ UV spectrum of the Methanolic extract of flowers of W. fruticosa Kurz. $\left(\mathrm{R}_{f}=0.38\right)$

2. UV spectrum of the Total aqueous extract of flowers of W. fruticosa Kurz. $\left(\mathrm{R}_{f}=0.32\right)$

3. UV spectrum of Ellagic acid from reference standard. $\left(\mathrm{R}_{f}=0.39\right)$ 


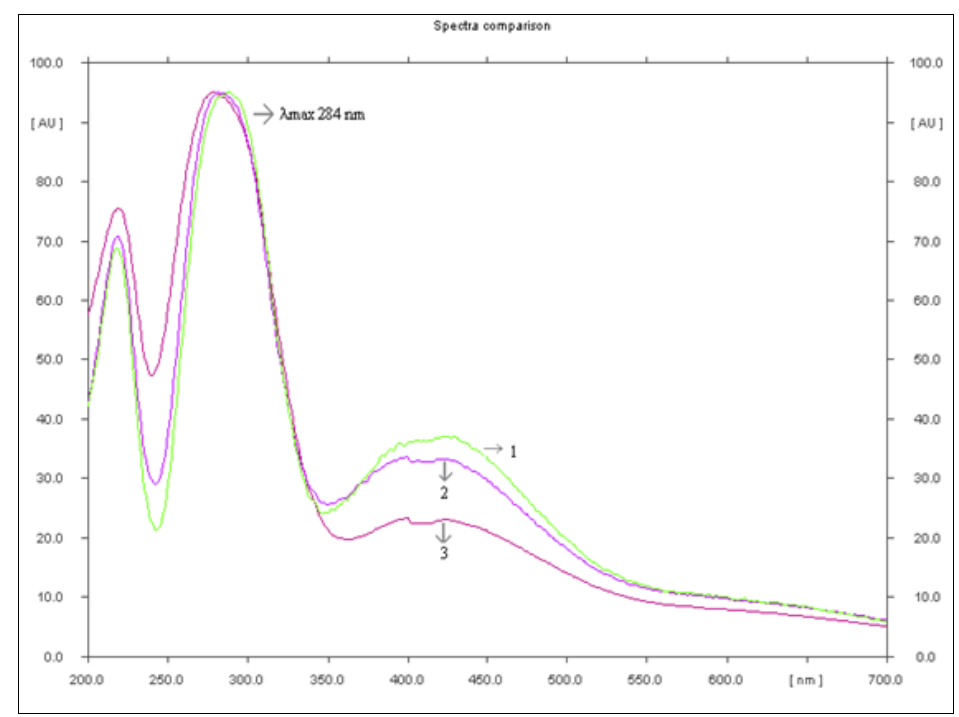

Fig 5: Superimposition of the UV spectra of Gallic acid (Reference Standard) the Methanolic and the Total aqueous extract of flowers of W.fruticosa Kurz.

1. UV spectrum of the Methanolic extract of flowers of W. fruticosa Kurz. $\left(\mathrm{R}_{\mathrm{f}}=0.53\right)$

2. UV spectrum of the Total aqueous extract of flowers of W. fruticosa Kurz. $\left(\mathrm{R}_{\mathrm{f}}=0.54\right)$

3. UV spectrum of Gallic acid from reference standard. $\left(\mathrm{R}_{\mathrm{f}}=0.53\right)$

\subsection{Analysis of Yashad bhasma}

Yashad bhasma (Baidyanath Co.) and the ointment prepared M3, M4 and A3 were analyzed for the $\mathrm{Zn}^{+2}$ content. Results are described in Table 5.

Table 5: Analysis of Yashad Bhasma

\begin{tabular}{|c|c|c|}
\hline Sample code & Sample & Zn (\%) w/w \\
\hline A & Yashad bhasma & 46.53 \\
\hline B & $\begin{array}{c}\text { Ointment containing Yashad } \\
\text { bhasma (1.25\% w/w) }\end{array}$ & 0.95 \\
\hline C & $\begin{array}{c}\text { Ointment containing Yashad } \\
\text { bhasma (0.62\% w/w) with } \\
\text { methanolic extract }(1 \% \text { w/w) }\end{array}$ & 0.45 \\
\hline D & $\begin{array}{c}\text { Ointment containing Yashad } \\
\text { bhasma }(0.62 \% \text { w/w) with Total } \\
\text { aqueous extract }(1 \% \text { w/w) }\end{array}$ & 0.56 \\
\hline
\end{tabular}

\subsection{Acute dermal toxicity study}

There were no signs of redness, itching, when the formulation M2 and A2 containing the highest concentrations of $2 \% \mathrm{w} / \mathrm{w}$ of Methanolic and total aqueous extract and also ointment containing yashad bhasma was applied on the shaved back of albino rats. This indicates that there is no observed toxicity and the extracts were found to be safe as no dermal toxicity symptoms were observed at the highest dose concentration $(2 \% \mathrm{w} / \mathrm{w})$.

\subsection{Excision wound study}

The results of wound healing activity by excision wound model are presented in Fig. 6. The values presented in the table represent percentage wound healing at $4,8,12,16,20$ days for control (simple ointment B.P. treated group.), standard (povidone iodine treated group) and the test groups $v i z$. the methanolic and total aqueous extract $(1 \%, \mathrm{w} / \mathrm{w}$ and $2 \%$, w/w), yashad bhasma and yashad bhasma with methanolic and total aqueous extract. It is observed that maximum wound contraction (100\% on day 20 ) is observed in case of animals treated with ointment M4. The wound contraction or healing was found to be significantly higher $(P<0.001)$ on days 8,12 and 16 as compared to the control group. Treatment with ointment M4 is found to be the most potent, as the period of epithelization is the least, that is, 20 days (Fig.7). The period of epithelization was also found to be significantly $(P<0.001)$ low as compared to standard group (22 days). The results indicate that formulation is better than the standard drug (Betadine) in wound healing potential.

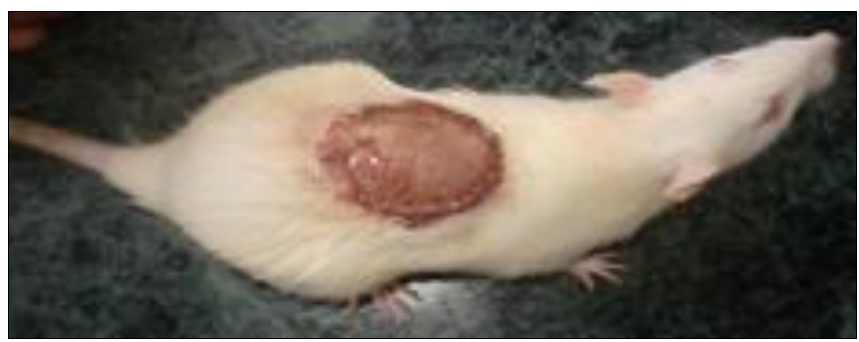

Fig 6: A circular excision wound on the day 0.

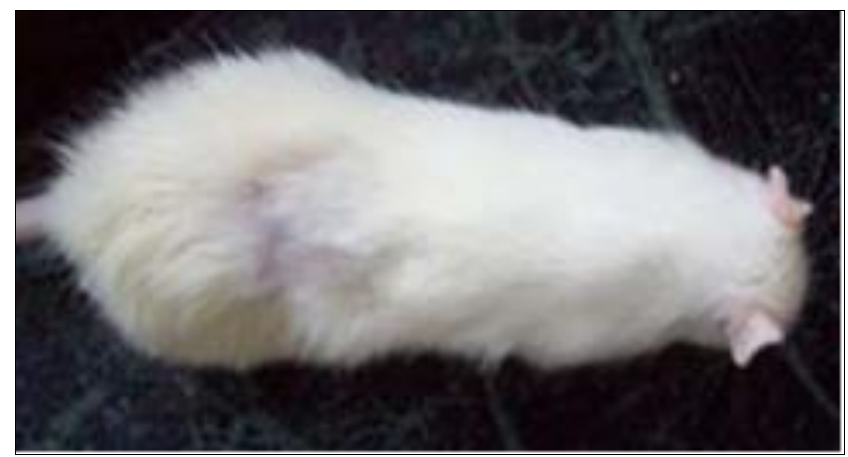

Fig 7: A circular excision wound after 20 day treatment.

\subsection{Incision wound study}

The results of the Incision wound healing studies are presented as mean weight in gram $\pm \mathrm{SEM}$ required to break open the resutured wound Fig. 8 and Fig 9 The animals treated with ointment M4 and A3 indicated significantly high $(P<0.001)$ tensile strength $595.8 \mathrm{gm}$ and $583.33 \mathrm{gm}$ as compared to the control group (387.5gm). 


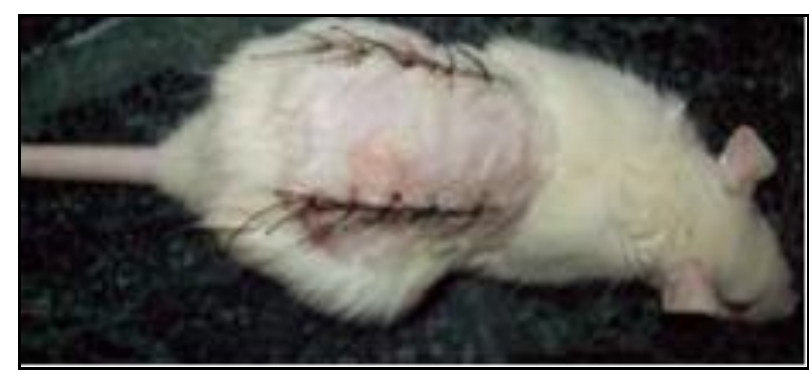

Fig 8: Incision wound on the day 0.

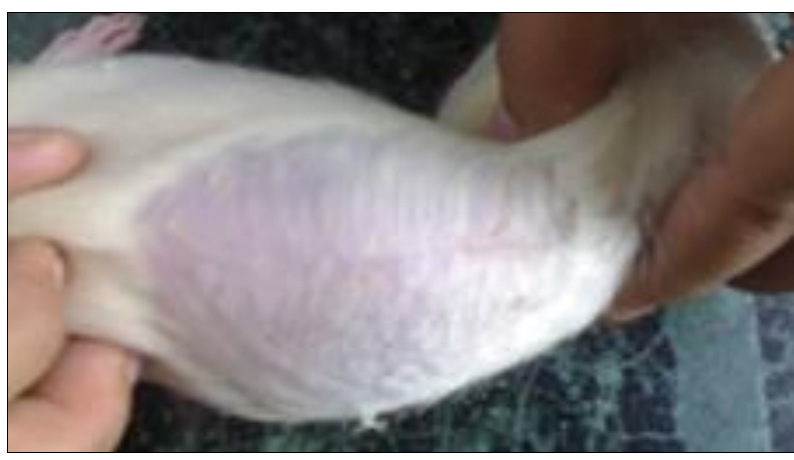

Fig 9: A completely healed incision wound after 8 day treatment.

\subsection{Estimation of Biochemical marker}

The results presented in (Table 4) reveal that the animals treated with ointment M4 and A3 showed significantly high $(P<0.001)$ levels of hydroxyproline $(20.69 \mathrm{~g} / 500 \mathrm{mg}$ and $24.98 \mathrm{~g} / 500 \mathrm{mg})$ as compared to the control group (13.41g/500mg).

Table 4: Effect of topical application of Methanolic and Total aqueous Extract of W. Fruticosa flowers on Hydroxyproline level in the scab of excision wound created in albino rats.

\begin{tabular}{|c|c|c|c|c|c|c|c|}
\hline \multirow{2}{*}{ Groups } & \multicolumn{7}{|c|}{ Hydroxyproline content $(\boldsymbol{\mu g} / \mathbf{5 0 0 m g})$} \\
\cline { 2 - 8 } & 1 & 2 & 3 & 4 & 5 & 6 & \\
\hline & \multicolumn{7}{|c|}{ Mean \pm S.E.M } \\
\hline CT & 13.25 & 13.05 & 12.56 & 14 & 13.40 & 14.20 & $13.41 \pm 0.24$ \\
\hline STD & 17.32 & 19.70 & 20.60 & 22.45 & 20.40 & 18.55 & $19.84 \pm 0.72$ \\
\hline M1 & 15.25 & 15.90 & 16.42 & 15.09 & 16.71 & 17.62 & $16.16 \pm 0.38^{* *}$ \\
\hline M2 & 20.75 & 24.21 & 21.87 & 22.87 & 22.80 & 23.06 & $22.59 \pm 0.47^{* *}$ \\
\hline M3 & 20.58 & 23.00 & 21.00 & 22.00 & 19.00 & 18.55 & $20.69 \pm 0.69^{* *}$ \\
\hline M4 & 24.52 & 26.24 & 27.22 & 25.38 & 27.39 & 26.75 & $26.25 \pm 0.45^{* *}$ \\
\hline A1 & 14.35 & 14.99 & 15.52 & 14.07 & 15.81 & 16.82 & $15.26 \pm 0.41^{*}$ \\
\hline A2 & 19.95 & 23.31 & 20.99 & 21.97 & 21.90 & 22.09 & $21.70 \pm 0.46^{* *}$ \\
\hline A3 & 23.62 & 25.34 & 26.32 & 23.48 & 26.39 & 24.75 & $24.98 \pm 0.51^{* *}$ \\
\hline F $_{\text {CAL }}$ & \multicolumn{9}{|c|}{76.92} & $\mathrm{~F}_{\mathrm{TAB}}$ & \multicolumn{5}{|c|}{3.17} \\
\hline
\end{tabular}

$\mathrm{n}=6$ Animals in each group

The treated groups are compared by ANOVA test with the control group.

$* * * P<0.001, * * P<0.01, * P<0.05$

\section{Discussion and Conclusion}

The basic principle of optimal wound healing is to minimize tissue damage and provide an adequate tissue perfusion and oxygenation, proper nutrition and moist wound healing environment to restore the anatomical continuity and function of the affected part. The results of excision wound model indicate that in the first 4 days there is no significant increase in the wound contraction in all the groups as compared to the control group. The results of the 8th day indicate that there is significant $(P<0.001)$ increase in the percentage wound contraction in the group treated with standard drug that is povidone iodine, (M4 and A3), revealing that the extract has ability to induce cellular proliferation, as the second phase of wound healing is proliferative phase. Hydroxyproline is an amino acid which is required for synthesis of protein collagen. Hydroxyproline is a major component of the protein collagen. Hydroxyproline content has been used as an indicator to determine collagen synthesis (Bergman and Loxley., 1963) ${ }^{[2]}$. The hydroxyproline levels in different groups were proportional to the tensile strength of the healed wounds in those groups. Hydroxyproline is one of the biomarkers indicating wound healing process, as the content of the same is increased on 10th day. The increased hydroxyproline content in the scab of the animals treated with ointment M4 and A3 support the wound healing process. Out of these ointments, ointment M4 and A3 is found to be the most effective. The increase in tensile strength of wounded skin indicates the promotion of collagen fibers. Highest tensile strength of the wounded skin was observed in the animals treated with ointment M4 and A3. The increased tensile strength reveals that the disrupted surfaces are firmly knit by collagen.

Ointment M4 and A3 is found to be the most effective due to presence of $\mathrm{Zn}^{+2}$ in bhasma and presence of Ellagic acid and Gallic acid in methanolic and total aqueous extract.

Zinc is a trace mineral, a component of many enzymes, including DNA and RNA polymerases, Matrix metalloproteinases ((MMPs) and is also required for protein synthesis, DNA synthesis, mitosis, and cell proliferation. The MMPs play an important role in tissue remodeling associated with various physiological and pathological processes such as morphogenesis, angiogenesis and tissue repair. Many of these zinc-dependent processes are required for wound healing, such as collagen synthesis and cell division. Consequently, zinc forms one of essential nutrients for normal wound healing (Andrews, Marti, GallagherAllred and Charlette, 1999) ${ }^{[1]}$.

Chemically, W. fruticosa Kurz. flower is a rich source of tannins. The constituents like tannins viz Ellagic acid and Gallic acid have major role in pharmacological activities. The proliferative phase is characterized by granulation tissue proliferation formed mainly by fibroblast and the angiogenesis process. In the proliferative phase, angiogenesis is essential for the provision of oxygen and metabolites to tissues. The flower has also exhibited Antifertility, and In vitro Anti-bacterial, which prevent microbial infection of wound. Phytochemical analysis revealed presence of polyphenolic compounds like tannins and these are also reported to have good wound healing activity (Muthusamy et al., 2008) ${ }^{[16]}$. Tannins are known for their astringent activity (Hagermann A. E., 2002) ${ }^{[8]}$ which may also be responsible for Anti-bacterial activity.

\section{References}

1. Andrews Marti, Gallagher-Allred, Charlette. Role of Zinc in Wound Healing, Advances in Wound Care. 1999; 12:137-138.

2. Bergman I, Loxley R. Two improved and simplified methods for the spectrophotometeric determination of hydroxyproline. Safety in Mine Research Establishment, Ministry of Power, Sheffield, England. 1963; 35(12):1961-1965.

3. Chandan BK, Saxena AK, Shukla S, Sharma N, Gupta DK, Singh K et al., Hepatoprotective Activity of Woodfordia fruticosa Kurz Flowers against Carbon 
Tetrachloride induced Hepatotoxicity, Journal of Ethno pharmacology. 2008; 119:218-224.

4. Das PK, Goswami S, Chinniah A, Panda N, Banrejee S, Sahu NP, Achari B. Woodfordia fructicosa: Traditional Uses and Recent Findings, Journal of Ethano pharmacology. 2007; 110:189-199.

5. Deodhar AK, Rana RE. Surgical physiology of wound healing: a review. Journal of Postgraduate Medicine. 1997; 43:52-56.

6. Diwan PV, Reddy BS, Reddy RKK, Naidu VGM, Madhusudhana K, Agwane SB et al., Evaluation of antimicrobial, antioxidant and woundhealing potentials of Holoptelea integrifolia. Journal of Ethno pharmacology. 2008; 115:249-256.

7. Govindrajan R, Kumar B, Vijaykumar M, Pushpangadan P. Ethanopharmacological approaches to wound healing-exploring medicinal plants of India. Journal of Ethno pharmacology. 2007; 114:103-113.

8. Hagermann AE, "Tannin Chemistry" in "Tannin handbook", USA, 2002, 36-42.

9. Kadota S, Takamori Y, Kikuchi T, Motegi A, Ekimotob H. Woodfruticosin, an Inhibitor of DNA Topoisomerase II from Woodfordia fruticosa kurz. 1997; 19:361-365.

10. Khushalani H, Tatke P, Singh KK. Antifertility Activity of Dried Flowers of Woodfordia fruticosa kurz, Indian Journal of Pharmaceutical Science. 2006; 68:528-529.

11. Kokane DD, More RY, Kale MB, Nehete MN, Mehendale PC, Gadgoli CG. Evaluation of wound healing activity of root of Mimosa pudica. Journal of Ethno pharmacology. 2009; 124:311-315.

12. Kroes BH, Berg AJJ, Van den, Abeysekera AM, De Silva KTD, Labadie RP. Fermentation in Traditional Medicine: The Impact of Woodfordia fruticosa Flowers on the Immuno modulatory Activity, and the Alcohol and Sugar Contents of Nimba arishta, Journal of Ethno pharmacology. 1993; 40:117-125.

13. Mandelbaum SH, Di Santis EP, Mandelbaum, MHSA. Cicatrization: current concepts and auxiliary resources-Part I. Anais Brasileiros de Dermatologia. 2003; 72:393-410.

14. Mavioso C. Noc, oes $b^{\prime}$ asicas sobre feridas e cicatrizac, ao. http://www.gaif.net/feridasecicatriz.pdf (accessed in 10/2007), 2003.

15. Mukherjee PK, Verpoorte R, Suresh B. Evaluation of in vivo wound healing activity of Hypericum patulum (Family: Hypericaceae) leaf extract on different wound model in rats. Journal of Ethno pharmacology. 2000; 70:315-321.

16. Muthusamy SK, Kirubanandan S, Sripriya Sehgal PK. Triphala pramotes healing of infected full-thickness dermal wound. Journal of Surgical Research. 2008; 144:94-101.

17. Nayak BS, Anderson M, Pereire P. Evaluation of wound healing potential of Catharanthus roseus leaf extract in rats. Fitoterpia. 2007; 78:540-544.

18. OECD guidelines for testing of chemicals, 1987, February. Acute Dermal Toxicity, 402, 1-7.

19. Parekh J, Chanda S. In Vivtro Antibacterial Activity of the Crude Methanol Extract of Woodfordia fruticosa Kurz Flowers, Brazilian Journal of Microbiology. 2007; 38:204-207.

20. Schwartz SI. "Skin and Subcutaneous Tissue", Schwartz's Principles of Surgery, The McGraw-Hill
Publishing House, New York, $8^{\text {th }}$ edition, 2006, 1-5. 